\title{
Analise físico-química de frutos de achachairu coletados em diferentes partes da planta
}

\author{
Márcio Silva Melo ${ }^{1}$, Cleiton Gredson Sabin Benett ${ }^{1}$, Bruno Silva Melo ${ }^{1}$, Samara Leticia \\ Oliveira Lourenço ${ }^{1}$, Frederico Severino Barboza ${ }^{1}$ \\ ${ }^{1}$ Universidade Estadual de Goiás, Câmpus Ipameri, Ipameri, Goiás, Brasil. E-mail: marciosilvagemeo@gmail.com, \\ cleiton.benett@gmail.com, brunosilvagemeo@gmail.com, samara_lourenco_@hotmail.com, sbfrederico@gmail.com,
}

Recebido: 28/10/2017; Aceito: 01/11/2017

\begin{abstract}
RESUMO
O achachairu, também conhecido como mangostinho, é originária da Bolívia cujo nome científico é Garcinia humilis, pertence à família Clusiaceae. O presente trabalho teve como propósito avaliar a qualidade físico-química de frutos de achachairu em diferentes partes da planta. O experimento foi conduzido no laboratório da Universidade Estadual de Goiás, Câmpus Ipameri, localizado no município de Ipameri-GO. O delineamento experimental utilizado foi o inteiramente casualizado, com três partes de coleta de frutos na planta (superior, mediana e base), sendo cada repetição constituída de três plantas. Os frutos de mangostinho foram utilizados de árvores provenientes do pomar da própria área experimental do Câmpus. Foram realizadas as seguintes avaliações físicas e químicas: massa de frutos, massa de sementes, diâmetro de fruto, $\mathrm{pH}$, sólidos solúveis totais ( ${ }^{\circ} \mathrm{Brix}$ ), acidez total titulável, razão SS/AT e rendimento de polpa. Os dados foram submetidos à análise de variância e as médias comparadas pelo teste de Tukey a 5\% de probabilidade. Nas condições avaliadas do experimento os frutos adquiridos da parte superior da copa são os mais indicados tanto para a comercialização in natura como para o processamento industrial, pois obtiveram melhores qualidades pós-colheita nos parâmetros avaliados.
\end{abstract}

Palavras-chave: Garcinia humilis, mangostinho, parte aérea.

\section{Physical-chemical analysis of achachairu fruits collected in different plant parts}

\begin{abstract}
The Achachairu, also known as mangostinho, is originally from Bolivia whose scientific name is Garcinia humilis, belongs to the family Clusiaceae. The purpose of this study was to evaluate the physical-chemical quality of achachairu fruits in different parts of the plant. The experiment was carried out in the laboratory of the State University of Goiás, Câmpus Ipameri, located in the municipality of Ipameri-GO. The experimental design was completely randomized, with three parts of fruit collection in the plant (upper, middle and base), each replicate being composed of three plants. Mangosteen fruits were used from trees from the orchard of the Campus experimental area. The following physical and chemical evaluations were performed: fruit mass, seed mass, fruit diameter, $\mathrm{pH}$, total soluble solids ( ${ }^{\circ} \mathrm{Brix}$ ), total titratable acidity, SS / AT ratio and pulp yield. The data were submitted to analysis of variance and the means compared by the Tukey test at $5 \%$ probability. In the evaluated conditions of the experiment the fruits acquired from the upper part of the crown are the most indicated both for the commercialization in natura and for the industrial processing, since they obtained better postharvest qualities in the evaluated parameters.
\end{abstract}

Key words: Garcinia humilis, mangostinho, shoot. 


\section{Introdução}

A preocupação com uma dieta mais equilibrada e o sabor único e diferenciado dos frutos tem gerado crescente procura dos consumidores e apreciadores de frutas exóticas, movimentando a economia brasileira. Dentre essas plantas exóticas para produção de frutos, o achachairu (Garcinia humilis), vem ganhando destaque na produção em escala comercial nas diversas regiões do Brasil, devido às condições climáticas e de solo satisfatórias para o desenvolvimento das plantas e produção dos frutos.

O achachairu é originário da Bolívia, pertence ao gênero Garcinia e à família Clusiaceae. Apresenta vários nomes populares como bacupari boliviano, chachairú, ibaguazú, cachicheruqui, mangostinho, tapacuarai ou tatairu (JANICK; PAULL, 2008). É uma planta exótica introduzida no Brasil no século XX, pode ser encontrada nos estados de Minas Gerais, São Paulo, Pernambuco, Pará e Goiás. É adaptada ao clima tropical e subtropical, mas se ajusta bem em outros climas, com isso, pode ser cultivada em todas as regiões brasileiras (BARBOSA et al., 2008).

Os frutos são globoso-oblongos, a base peduncular do fruto é estreita e a calicinal mais larga. São amareloalaranjados, com casca grossa, lisa, firme e resistente; internamente a casca é creme-palha. A polpa, não adere à casca, é branca, suculenta e de textura mucilaginosa, sendo que após retirada dos frutos se oxida rapidamente. O sabor lembra um pouco ao do araçá; é bem agradável e adocicado (BARBOSA et al., 2008). As sementes são desuniformes, de 1 a 3 por fruto, esbranquiçadas, alongadas e grandes. No nordeste brasileiro, a maturação dos frutos ocorre de fevereiro a abril, são bastante resistentes ao transporte e de boa conservação em geladeira comum (BARBOSA et al., 2008).

Essa espécie tem diversos usos como: cicatrizante, digestivo, laxante, também para o combate do reumatismo, úlcera gástrica e inflamação. Além disso, podem ser extraídas de suas folhas e frutos substâncias como biflavanóides e benzofenonas apontando seu potencial imunotóxico, anti-inflamatório, antioxidante e anticancerígeno (CURY et al., 2016).

Com o aumento da procura de frutos exóticos, aumenta também a produção desses frutos no Brasil, tornando uma boa alternativa para a complementação da renda familiar de vários produtores. Para sucesso no mercado, o fruto precisa ter qualidade e satisfazer o paladar da população. Diante disso existem alguns métodos que são utilizados para indicar a qualidade pós colheita do fruto, como a caracterização física e química (LIMA et al., 2012).

Nos estudos feitos por Nascimento et al. (2008), avaliando as características físicas e químicas dos frutos de mamey para o mercado, observaram que entre as 13 plantas analisadas, a planta 3 foi a que obteve melhores resultados para as características físicas e a planta 9 teve maior aptidão para a comercialização.

Coelho et al. (2011) obtiveram as características pós colheita do maracujá-amarelo (Passiflora edulis $f$. flavicarpa Degener) utilizando o mínimo de quantidade de amostras, sendo que essa quantidade pode ser de aproximadamente 20 frutos, onde as mesmas têm condições de expressar a qualidade física como diâmetro, peso de frutos e produção de frutos.

Em projeto desenvolvido por Lima et al. (2012) para adquirir dados da qualidade pós-colheita do fruto de Physalis peruviana L. avaliaram o tempo de colheita em 2 períodos de plantio. Obtendo-se como melhores atributos químicos e físicos os frutos coletados aos 210 e 240 dias após o transplantio. Portanto, o presente trabalho teve como propósito avaliar a qualidade físicoquímica de frutos de achachairu em diferentes partes da planta.

\section{Material e Métodos}

O experimento foi conduzido no laboratório da Universidade Estadual de Goiás, Câmpus Ipameri, localizado no município de Ipameri-GO, cujas coordenadas geográficas são $17^{\circ} 43^{\prime} 04^{\prime}$ ' Sul, 48 $08^{\circ} 43^{\prime}$ ', Oeste e altitude de $794 \mathrm{~m}$. O clima da região, segundo a classificação de Köppen-Geiger (CARDOSO et al., 2014) é definindo como clima tropical (Aw) constando estação seca no inverno. O solo da área experimental foi classificado como Latossolo VermelhoAmarelo Distrófico (SANTOS et al., 2013).

O delineamento experimental utilizado foi $o$ inteiramente casualizado, com três partes de coleta de frutos na planta (superior, mediana e base), sendo cada repetição constituída de três plantas. Foram utilizados frutos de achachairu (Garcinia humilis) provenientes do pomar da própria área experimental da Universidade Estadual de Goiás, Câmpus Ipameri. Os frutos foram coletados da parte superior, mediana e da base da copa, conforme Figura 1.
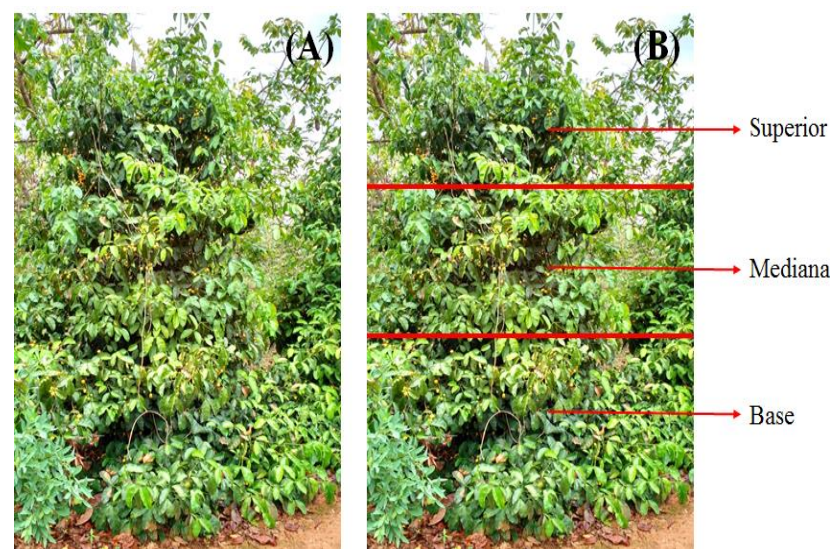

Figura 1. Planta em perfil (A) e detalhes das partes de coleta dos frutos em plantas de achachairu (B). Ipameri-GO, 2016. 
Foram realizadas as seguintes avaliações físicas:

Massa de frutos: com amostras de 50 frutos por repetição em cada parte da planta e realizada a pesagem dos frutos em balança de precisão, expresso em gramas (g).

Massa de sementes: determinada a pesagem de 15 sementes por repetição em cada parte da planta, com o auxílio de balança de precisão, expresso em gramas (g).

Diâmetro de frutos: mensurados cinco frutos das três plantas coletados de três partes diferentes da copa (superior, mediana e base), com o auxílio de paquímetro digital, expresso em milímetros (mm).

Rendimento de polpa: utilizando a massa de 50 frutos de cada parte da planta, sendo valores expressos em porcentagem (\%) e com aplicando a seguinte equação:

$$
\text { Rendimento }(\%)=\frac{\text { massa da polpa }(\mathrm{g})}{\text { massa total do fruto }(\mathrm{g})} * 100
$$

Para as determinações de $\mathrm{pH}$, teor de sólidos solúveis totais e acidez total titulável dispôs-se da metodologia proposta pelo Instituto Adolfo Lutz (2008). Foram realizadas as seguintes avaliações químicas:

$p H$ : foi realizada a leitura com o pHmetro digital, utilizando-se quinze frutos para cada parte da planta, mantendo a solução homogênea

Sólidos solúveis totais (SS): utilizou-se refratômetro portátil Atto WYT-4, utilizando quinze frutos para cada parte da planta e os valores expressos em ${ }^{\circ}$ Brix.

Acidez total titulável (AT): determinada para cada parte da planta por titulação do filtrado, utilizando quinze frutos.

Razão SS/AT: divisão do sólido solúvel total pela acidez total titulável.

Os dados apresentados foram adequados para submissão à análise de variância e as médias comparadas pelo teste de Tukey a 5\% de probabilidade. Foi utilizado o programa de análise estatística Sanest.

\section{Resultados e Discussão}

Estão descritos na Tabela 1: os parâmetros avaliados de massa dos frutos em gramas, massa de sementes em gramas, diâmetro de fruto em milímetros, $\mathrm{pH}$, teor de sólidos solúveis totais com os resultados expressos em ${ }^{\circ}$ Brix, acidez total titulável, razão SS/AT e rendimento de polpa para a averiguação da qualidade pós-colheita.

A massa dos frutos colhidos na extremidade superior da copa $(8,50 \mathrm{~g})$ foi significativamente diferente $(\mathrm{p}<0,05)$ em relação aos frutos da mediana e base da planta; entre os dois últimos não houve diferença. É possível afirmar em termos fisiológicos que a relação fonte dreno é mais favorável aos frutos da ponta da copa, os quais provavelmente absorvem mais assimilados que os demais. Alguns autores relatam que o parâmetro de maior importância é a massa, pois os frutos mais encorpados atraem com maior facilidade o consumidor (LIRA JUNIOR et al., 2010). Os valores do presente trabalho são superiores ao encontrados por Oliveira et al. (2011a) que observaram uma média de 4,33 g em frutos de camapu (Physalis angulata L.). Barbosa e Artioli (2007) verificaram valores superiores ao atual estudo com média de $30 \mathrm{~g}$ por fruto.

Para a massa das sementes não houve diferença significativa entre as médias dos indivíduos obtidos da parte superior, mediana e base da copa, os quais variaram entre 5,60 e 5,70 g. Pode-se estabelecer uma correlação com o peso da massa dos frutos, em que a massa das sementes não influencia diretamente no peso da massa dos frutos; desta forma é possível indicar que quanto ao armazenamento de energia e vigor praticamente todas contêm o mesmo.

Para o diâmetro de fruto é possível observar que o resultado menos favorável é para os frutos colhidos da base da copa com uma média de $23,6 \mathrm{~mm}$, sendo que os frutos da parte superior e mediana apresentaram média de 27,9 e $28,3 \mathrm{~mm}$ respectivamente. Frutos com diâmetros maiores apresentam melhor comércio para vendas em relação aos menores.

Tabela 1. Características físicas-químicas de frutos de Achachairu maduros colhidos em diferentes partes da planta. Ipameri-GO, 2016.

\begin{tabular}{|c|c|c|c|c|}
\hline Parâmetros & Superior & Mediana & Base & $\begin{array}{c}\text { Coeficiente } \\
\text { Variação }(\%)\end{array}$ \\
\hline Massa de frutos (g) & $8,50 \mathrm{a}$ & $7,20 \mathrm{~b}$ & $7,21 \mathrm{~b}$ & 7,04 \\
\hline Massa de sementes (g) & $5,60 \mathrm{a}$ & $5,60 \mathrm{a}$ & $5,70 \mathrm{a}$ & 4,24 \\
\hline Diâmetro de fruto (mm) & 27,92 a & $28,30 \mathrm{a}$ & $23,65 \mathrm{~b}$ & 6,21 \\
\hline $\mathrm{pH}$ & $2,80 \mathrm{a}$ & $2,74 \mathrm{a}$ & $2,66 \mathrm{a}$ & 3,06 \\
\hline${ }^{\circ} \operatorname{Brix}(\%)$ & $16,36 \mathrm{a}$ & $15,17 \mathrm{ab}$ & $14,08 \mathrm{~b}$ & 5,10 \\
\hline Acidez total titulável (\%) & $1,08 \mathrm{~b}$ & $1,40 \mathrm{ab}$ & $1,90 \mathrm{a}$ & 24,60 \\
\hline Razão SS/AT & $16,42 \mathrm{a}$ & $11,12 \mathrm{ab}$ & $7,82 \mathrm{~b}$ & 27,00 \\
\hline Rendimento de polpa (\%) & $21,01 \mathrm{a}$ & $13,58 \mathrm{~b}$ & $14,66 \mathrm{~b}$ & 33,70 \\
\hline
\end{tabular}

Médias seguidas de mesma letra na linha, para cada fator estudado, não diferem entre si pelo teste de Tukey a 5\% de probabilidade. 
Experimentos desenvolvidos por Oliveira et al. (2011b) descreveram valor médio menores para frutos de camapu com cerca de 18,66 mm, sendo possível estabelecer uma analogia entre o peso da massa e o diâmetro dos frutos; na medida em que se observa aumento do diâmetro observa-se também maior peso da massa ou vice-versa.

No parâmetro $\mathrm{pH}$ não houve diferença significativa entre os tratamentos, variando de 2,66 a 2,80. Estes valores indicam que $o$ sabor do fruto possui característica bastante acidificada, aconselhado para a fabricação de sucos e outros produtos industrializados. Em relação à outros trabalhos os valores são menores, pois Oliveira et al. (2011b), avaliando sapoti em pó liofilizado encontraram valor de 5,58. Barbosa e Artioli (2007) constataram valores maiores em Achachairu; cerca de $\mathrm{pH} 4,0$.

Para a avaliação dos sólidos solúveis totais (SS) houve efeito significativo $(\mathrm{p}<0,05)$ nos frutos coletados na parte superior $\left(16,36^{\circ} \mathrm{Brix}\right)$ da planta em relação aos frutos da base (14,08 $\left.{ }^{\circ} \mathrm{Brix}\right)$, não diferindo, por sua vez, dos frutos da parte mediana $\left(15,17^{\circ}\right.$ Brix) (Tabela 1). Os valores encontrados neste trabalho são semelhantes aos encontrados por Ardaya (2009), em estudos com mangostin (Garcinia humilis) do tipo secto de 16,4 ${ }^{\circ}$ Brix. Palapol et al. (2009) relataram valores superiores para mangostão (Garcinia mangostana L.) com aproximadamente $18{ }^{\circ}$ Brix. Guimarães e Silva (2008) observaram valor de $43{ }^{\circ}$ Brix em frutos de murici desidratados osmoticamente.

Para a acidez total titulável de frutos de achachairu foi possível identificar que os frutos da base $(1,08 \%)$ das plantas apresentaram diferenças estatísticas em comparação aos frutos da parte superior $(1,90)$, estes não diferindo dos frutos da parte mediana (Tabela 1). Desta forma pode-se verificar que os frutos de achachairu apresentam baixa acidez, apresentando-se satisfatórios para o consumo in natura, visto que frutos com maior acidez são mais favoráveis para o processamento industrial. Nascimento et al. (2008) verificaram valores inferiores ao presente experimento em frutos de mamey, os quais expressaram médias extremamente baixas de acidez total titulável com $0,5184 \%$ e os demais $0,155 \%$. Ardaya (2009), em pesquisa realizada com achachairu encontraram valores próximos aos deste trabalho. Vários aspectos como o tipo de cultivar, altitude e condições climáticas podem influenciar nas variáveis como sólidos solúveis totais, acidez total titulável e massa de frutos (YILMAZ et al., 2009).

As razões SS/AT apresentaram efeito significativo $(\mathrm{p}<0,05)$ para os frutos obtidos da extremidade superior da copa com média de 16,42 , seguido do meio da copa com 11,12 e da base com valor de 7,82 (Tabela 1). A razão SS/AT é um dos parâmetros que melhor descreve o gosto pois associa o teor de açúcares e ácidos contidos no fruto; estes teores podem ser influenciados pela posição que os frutos se encontram na planta.

Os valores da relação SS/AT encontrados neste trabalho são similares aos de Ardaya (2009), onde encontraram médias para "Achachairucilo" $(11,02)$ e "Achachairu pequeno globoso" (11,39). Palapol et al. (2009) descreveram médias superiores para frutos de mangostão (Garcinia mangostana L.) com valor de 23,7 para a relação $\mathrm{SS} / \mathrm{AT}$.

A variável rendimento de polpa foi influenciada significativamente $(p<0,05)$ para os frutos da parte superior em relação aos frutos da mediana e base (Tabela1). Observou-se que os frutos da parte superior apresentaram maior rendimento da polpa; 54,7 \% maior aos frutos da parte mediana da planta. Essa variável em frutos de achachairu apresenta baixo rendimento em relação a outros frutos exóticos, tornando-se necessária uma maior quantidade de frutos para a realização do processamento.

\section{Conclusões}

Nas condições avaliadas do experimento os frutos adquiridos da parte superior da copa são os mais indicados tanto para a comercialização in natura como para o processamento industrial, pois obtiveram melhor qualidade pós-colheita nos parâmetros avaliados

\section{Agradecimentos}

À Universidade Estadual de Goiás (UEG), Campus Ipameri, pelo suporte na condução do projeto e pela bolsa de mestrado concedida ao primeiro autor.

\section{Referências Bibliográficas}

ARDAYA, B. D. El cultivo de achachairu Garcinia humilis: manual de recomendaciones. Santa Cruz, Bolívia: Centro de Investigacíon Agricola Tropical, 2009. 101 p. (Manual de Recomendaciones).

BARBOSA, E.; ARTIOLI, F. A. A fruta achachairú. 2007. Artigo em Hypertexto. Disponível em: <http://www.in fobibos.com/Artigos/2007_1/achachairu/index.htm>. Acesso em: 06 de jun. de 2017.

BARBOSA, W.; CHAGAS, E. A.; MARTINS, L.; PIO, R.; TUCCI, M. L. S.; ARTIOLI, F. A. Germinação de sementes e desenvolvimento inicial de plântulas de achachairu. Revista Brasileira de Fruticultura, Jaboticabal-SP, v. 30, n. 1, p. 263-266, 2008.

CARDOSO, M. R. D.; MARCUZZO, F. F. N.; BARROS, J. R. Classificação climática de Köppen-Geiger para o Estado de Goiás e o Distrito Federal. ACTA Geográfica, Boa Vista-RR, v. 8, n. 16, p. $40-55,2014$. 
COELHO, A. A.; OLIVEIRA, E. M. S.; RESENDE, E. D. Dimensionamento amostral para a caracterização da qualidade pós colheita do maracujá-amarelo. Revista Ceres, ViçosaMG, v. 58, n. 1, p. 23-28, 2011.

CURY, G. C.; GISBERT, M. C. A.; PORCEL, W. J. R. Um estudo da fruta comestível de Garcinia gardeneriano. Revista Boliviana de Química, La Paz- Bolívia, v. 33, n. 5, p. 158$163,2016$.

GUIMARÃES, M. M; SILVA, M. S. Valor nutricional e características químicas e físicas de frutos de murici-passa (Byrsonima verbascifolia). Ciência e Tecnologia de Alimentos, Campinas-SP, v. 28 n. 4, p. 817-821, 2008.

IAL. INSTITUTO ADOLFO LUTZ. Normas analíticas do IAL: métodos químicos e físicos para análise de alimentos. 5. ed. IAL: São Paulo-SP, 2008. 1020 p.

JANICK, J.; PAULL, R. E. Rheedia laterifolia - Achachairú. In: JANICK, J.; PAULL, R. The encyclopedia of Fruit $\&$ Nuts. 3. ed. London, UK: CAB International, 2008. p. 272273.

LIMA, C. S. M.; GALARÇA, S. P.; BETEMPS, D. L.; RUFATO, A. R.; RUFATO, L. Avaliação física, química e fitoquímica de frutos de Physalis, ao longo do período de colheita. Revista Brasileira de Fruticultura, Jaboticabal-SP, v. 34, n. 4, p. 1004-1012, 2012.

LIRA JUNIOR, J. S.; BEZERRA, J. E. F.; LEDERMAN, I. E.; MOURA, R. J. M. Produção e características físicoquímicas de clones de cirigueleira na Zona da Mata Norte de Pernambuco. Revista Brasileira de Ciências Agrárias, Recife-PE, v. 5, n. 1, p. 43-48, 2010.
NASCIMENTO, V. E.; MARTINS, A. B. G.; HOJO, R. H. Caracterização física e química de frutos de mamey. Revista Brasileira de Fruticultura, Jaboticabal-SP, v. 30, n. 4, p. 953-957, 2008.

OLIVEIRA, J.A.R.; MARTINS, L. H. S.; VASCONCELOS, M. A. M.; PENA, R. S.; CARVALHO, A. V. Caracterização física, físico-química e potencial tecnológico de frutos de camapu (Physalis angulata). Revista Brasileira de Tecnologia Agroindustrial, Curitiba-PR, v. 5, n. 2, p. 573583, 2011a.

OLIVEIRA, V. S.; AFONSO, M. R. A.; COSTA, J. M. C. Caracterização físico-química e comportamento higroscópico sapoti liofilizado. Revista Ciência Agronômica, FortalezaCE, v. 42, n. 2, p. 342-348, 2011 b.

PALAPOL, Y.; KETSA, S.; STEVENSON, D.; COONEY, J. M.; ALLAN, A. C.; FERGUSON, I. B. Colour development and quality of mangosteen (Garcinia mangostana L.) fruit during ripening and after harvest. Postharvest Biology and Technology, Nova Zelândia, v. 51, n.3, p. 349-353, 2009.

SANTOS H. G.; JACOMINE P. K. T.; ANJOS L. H. C.; OLIVEIRA V. A.; LUMBRERAS J. F.; COELHO M. R.; ALMEIDA J. A.; CUNHA T. J. F.; OLIVEIRA J. B. Sistema brasileiro de classificação de solos. Brasília-DF: Embrapa Solos, 2013. 353p.

YILMAZ, K. U.; ERCISLI, S.; ZENGIN, Y.; SENGUL, M. KAFKAS, E. Y. Preliminary characterisation of cornelian cherry (Cornus mas L.) genotypes for their physico-chemical properties. Food Chemistry, Netherlands, v. 114, n. 2, p. 408412, 2009. 